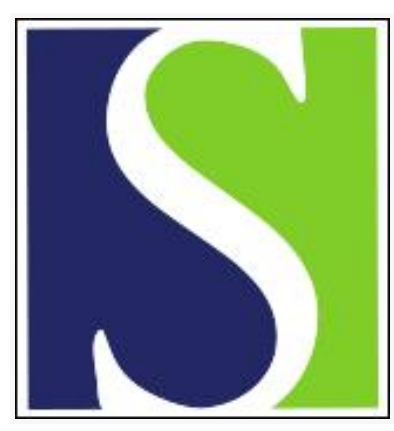

Scand J Work Environ Health 1998;24(6):495-502

https://doi.org/10.5271/sjweh.374

Issue date: Dec 1998

Vibrotactile sense in the hand-arm vibration syndrome by Strömberg T, Dahlin LB, Lundborg $G$

Key terms: hand; neurophysiology; occupational disease; peripheral nervous system disease; sensory threshold; vibration

This article in PubMed: www.ncbi.nlm.nih.gov/pubmed/9988092

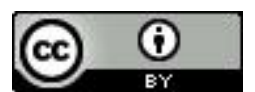




\title{
Vibrotactile sense in the hand-arm vibration syndrome
}

\author{
by Trygve Strömberg, MD, ${ }^{1,2}$ Lars B Dahlin, MD, ${ }^{1}$ Göran Lundborg, MD
}

\author{
Strömberg T, Dahlin LB, Lundborg G. Vibrotactile sense in the hand-arm vibration syndrome. Scand J Work \\ Environ Health 1998;24(6):495-502.
}

\begin{abstract}
Objectives The purpose of this study was to investigate disturbances of the vibrotactile sense and their relation to clinical symptoms and findings among male symptomatic workers suffering from the hand-arm vibration syndrome.

Methods Ninety-six such patients were interviewed and given a clinical and tactilometric examination. The symptoms were classified according to the Stockholm Workshop Scale. A sensibility index was used to quantify vibrotactile sense in the tactilogram.

Results An abnormal sensibility index $(<0.8)$ was recorded for $57.3 \%$ of the patients (mean of 4 fingers), at least 1 finger being abnormal in $72.9 \%$ of the patients. The sensibility index did not statistically differ between the patients suffering from sensorineural symptoms and those with vibration white finger. The stages of sensorineural symptoms, according to the Stockholm Workshop Scale, corresponded with the sensibility index, whereas the stages of vibration white finger did not. There were significant differences in the sensibility index between the fingers, between the right and left hands, and between the fingers innervated by the ulnar and median nerves. Bilateral symptoms and cold intolerance were associated with considerable impairment of the vibrotactile sense. Clinical median nerve involvement in the carpal tunnel was not reflected by the sensibility index.

Conclusions There is a considerable degree of neural involvement in all symptomatic vibration-exposed patients irrespective of symptoms. As symptoms progress, the severity of sensorineural symptoms, but not of vibration white finger, is reflected by the sensibility index. Cold intolerance is strongly related to nervous involvement and should be noted in the patient history. Tactilometry should be performed on 1 median and 1 ulnar nerve-innervated finger of both hands, as an examination of 1 finger alone may be misleading.
\end{abstract}

Key terms hand, neurophysiology, occupational diseases, peripheral nervous system diseases, sensory thresholds, vibration.

The hand-arm vibration syndrome represents a problem of increasing importance in modern society. The syndrome includes sensorineural, vasospastic, and neuromuscular symptoms, and the disease seems to have a progressive course with continued long-term use of vibrating tools $(1,2)$. After vibration-exposure has ceased, symptoms may be reversed, persist, or even progress (3, 4). The hand-arm vibration syndrome is often seen among young workers facing several additional decades of work. Individual susceptibility to the adverse effects of vibration may be of importance to the development of symptoms (5). If serious and perhaps irreversible hand problems are to be avoided, it is essential to establish a firm diagnosis early in the disease.
Methods currently used to diagnose the neurological component of the syndrome are - apart from a careful history being taken and a thorough clinical examination being performed -- esthesiometry, neurophysiological tests, and the assessment of thermal and vibration detection thresholds (6). Disturbances of the vibrotactile sense are early signs of vibration-induced nerve injury (7-9). Vibration thresholds can be detected using either singleor multiple-frequency techniques $(10-12)$. The use of multiple frequencies and the investigation of several fingers allow various receptor populations to be studied and both the median and the ulnar nerves to be evaluated $(6$, 13). The purpose of this study was to investigate disturbances of the vibrotactile sense and their relation to

1 Department of Hand Surgery, Malmö University Hospital, Lund University, Malmö, Sweden.

2 Department of Orthopaedic Surgery, Kristianstad Central Hospital, Kristianstad, Sweden.

Reprint requests: Dr Trygve Strömberg, Department of Hand Surgery, Malmö University Hospital, S-205 02 Malmö, Sweden. [E-mail: Gertrud.Andersson@hand.mas.lu.se] 
clinical symptoms and findings among male symptomatic workers suffering from the hand-arm vibration syndrome.

\section{Subjects and methods}

\section{Patients and the clinical examination}

Ninety-six consecutively examined symptomatic men aged 23-61 (median 45) years were included in our study. None of them suffered from polyneuropathy, cervical radiculopathy, or other neurological (apart from suspected cases of carpal tunnel syndrome) or vascular diseases rendering them unsuitable. They had all been referred to the Department of Hand Surgery during 1991-1993 due to sensorineural symptoms, vasospastic problems, pain, or muscular weakness. All of them had been working with hand-held vibrating tools for various periods of time. Nineteen had been vibration-ex-

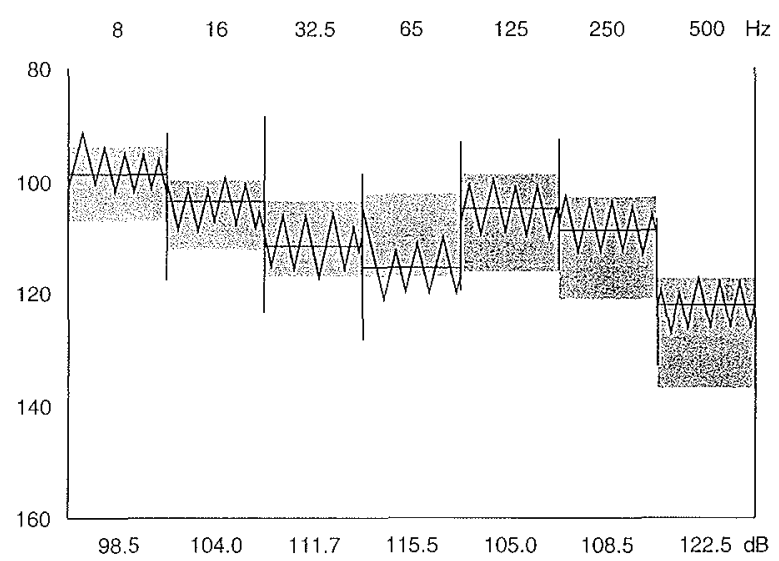

Figure 1. Normal tactilogram for the right little finger. The grey zone indicates a reference curve $( \pm 1 \mathrm{SD})$ corrected for age. The intensity of the vibration stimulus $(\mathrm{dB})$ is shown on the $y$-axis and the stimulation frequency $(\mathrm{Hz})$ is shown on the $x$-axis.

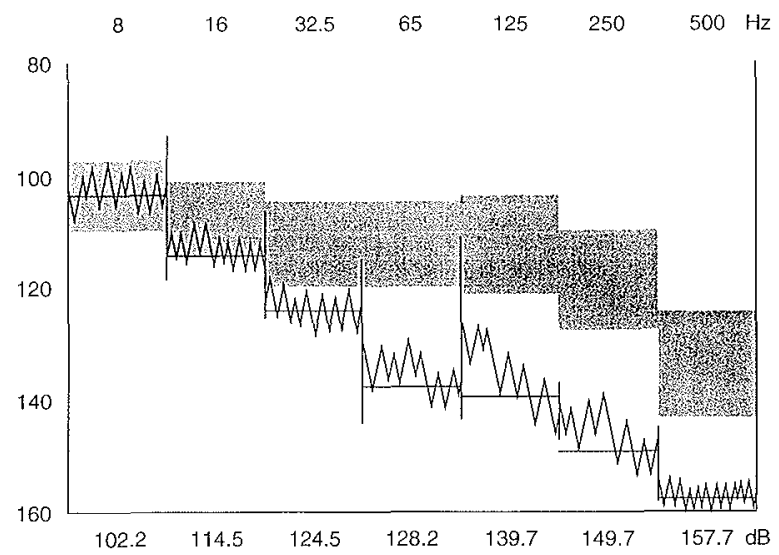

Figure 2. Tactilogram showing changes in the right little finger of a vibration-exposed symptomatic man. Note the altered slope of the curve and the increased thresholds evident in the higher frequencies in particular (sensibility index $=0.51$ ) posed for $\leq 10$ years, 25 for $11-20$ years, 24 for $21-30$ years, and 28 for $>30$ years. Several occupations were represented, as follows: 20 platers, 23 grinders and welders, 18 mechanics, 18 concrete and stone workers, 10 carpenters and electricians, and 7 truck drivers. All but 3 patients were right-handed.

A history was taken with regard to occupation, length of vibration exposure, and the duration and character of the symptoms. The symptoms were classified according to the Stockholm Workshop Scale $(1,2)$. The occurrence of cold intolerance, defined as pain and coldness of the fingers without blanching on exposure to cold, was also carefully asked about and noted. The clinical examination included the assessment of static 2-point discrimination, Tinel's sign, Phalen's test, and Allen's test. Weakness of the intrinsic muscles and reduced grip strength were considered to be present if the strength, based on the examiner's own subjective estimation, was reduced by half or more.

\section{Technique for assessing vibrotactile sense}

The tactilometer. A refined modification of previously described equipment $(8,9)$ was used to assess vibrotactile sense. The pulps of the index and the little fingers of both hands - innervated by the median and ulnar nerves, respectively - were subjected to sinusoidal vibration at the 7 frequencies, in ascending order, of $8,16,32.5,65$, 125,250 , and $500 \mathrm{~Hz}$, automatically delivered by the equipment (11). The patient was seated comfortably with his arm resting on a cushioned table, the pulp of his finger in contact with a vibrating probe, which was centrally placed in a small hole in the table. Using a hand switch, the patient was able to control the intensity and to track back and forth between levels of perception and nonperception. This way, a tactilogram was obtained (figure 1). The threshold at each frequency was defined as the midpoint between the upper and lower limena, expressed in decibels relative to $10^{-6} \mathrm{~m} / \mathrm{s}^{2}$. A complete test of a finger required $4-5$ minutes.

The tactilogram is graphically displayed on an inverted scale with low intensities (amplitudes) at the top and high intensities at the bottom (figure 1). Consequently a tactilogram in a low position indicates increased perception thresholds (ie, impaired vibrotactile sense). As frequencies increase, so do the thresholds, with the exception of 125 and $250 \mathrm{~Hz}$. The normal tactilogram therefore has the form of a slope interrupted by a peak at $125-250 \mathrm{~Hz}$ (figure 1 ). In nerve compression and in vibration-induced neuropathy a characteristic change appears in the shape of the curve. The highest frequencies are usually the first to be affected, while changes in the lower frequencies appear later (figure 2) $(7,9)$.

Quantitative assessment of vibrotactile sense. The tactilogram allows changes in the vibrotactile sense to be 
quantified in various ways. For each frequency the computer calculates and displays both the perception threshold and the "distance" between the threshold and the $\mathrm{x}$-axis. Changes within each frequency can therefore be analyzed individually. We have used a more composite measure. Results obtained from a reference population consisting of 171 men aged 19-75 years (14) are stored in the software of our equipment. The tactilogram is compared with a reference curve based on these data. The reference curve, constituting the mean sensory thresholds $( \pm 1$ SD), is automatically adjusted for age. With its corresponding range of variation, the curve is displayed on the screen as a grey zone. To facilitate visual evaluation, the tactilogram and the reference curve are superimposed on each other.

In order to express changes numerically in the whole tactilogram, we have used a sensibility index as a measure. It is defined as the ratio between the integrated areas under the test curve $\left(\operatorname{area}_{\mathrm{T}}\right)$ and under the reference curve $\left(\right.$ area $\left._{R}\right)(11)$. These areas, delimited by the perception thresholds, the $\mathrm{x}$-axis, and the $\mathrm{y}$-axis, are automatically calculated by the equipment. A sensibility index of 1.0 indicates a normal vibrotactile sense. As vibration perception thresholds increase, the area beneath the tactilogram decreases, as does the ratio area $_{\mathrm{T}}: \operatorname{area}_{\mathrm{R}}$, the result being a lower sensibility index. For about $10 \%$ of the reference population the sensibility index was below 0.8 . A sensibility index of $<0.8$ is therefore regarded as an indicator of abnormality.

\section{Statistical methods}

A split plot analysis of variance for repeated measurements was used to correct for intraindividual variations (ie, the 4 fingers) in a comparison of patients with sensorineural symptoms, vibration white finger and both, in a comparison of the right and left hands, and in a comparion of fingers innervated by the ulnar and median nerves. The method was also applied in a comparison between patients with and without cold intolerance. As compensation for asymmetry in the material, the sensibility index values were squared for these analyses. Similar split plot analyses of variance were performed within the subgroups of patients with bilateral and unilateral symptoms (not with respect to cold intolerance), as well as for the right hand only. In these subgroups the material was not asymmetrically distributed, and hence the sensibility index values were not squared. The presence or absence of symmetry in the material was evaluated on the basis of the residuals (ie, the differences between the individual sensibility index values and the mean sensibility index values within each group).

The Kruskal-Wallis nonparametric 1-way analysis of variance by ranks was used in analyses of the exposure time and clinical staging of the hand-arm vibration syndrome. In cases of $\mathrm{P}<0.05$ a complementary analysis with the Bonferroni correction was employed using the following formula (15):

$$
\left|\overline{R_{i}}-\overline{R_{j}}\right|>z_{\alpha / k(k-1)} \sqrt{\left(S_{\mathrm{r}}^{2}-C\right)(N-1-H) \frac{n_{i}+n_{j}}{n_{i} n_{j}(N-k)(N-1)}},
$$

where $\bar{R}_{i}=$ mean rank for group $i, \bar{R}_{j}=$ mean rank for group $j, z_{\alpha / k(k-1)}=z$-value for $\alpha / k(k-1)$ with $\alpha$ being the desired level for probability, $k=$ total number of groups compared, $S_{\mathrm{r}}^{2}=$ sum of squared ranks, $\mathrm{C}=\left[N(N+1)^{2}\right] /$ $4, N=$ total number of observations, $H=\mathrm{H}$-value derived from the Kruskal-Wallis analysis, $n_{i}=$ number of observations in group $i$, and $n_{j}=$ number of observations in group $j$.

All other symptoms and physical findings were analyzed using the Mann-Whitney U test. In the KruskalWallis test and in the Mann-Whitney $U$ test, the mean sensibility index of both hands and of the right hand were used. Fisher's exact test was employed to distinguish differences in the occurrence of the mean sensibility index of $<0.8$. The mean sensibility index of 4 fingers was compared with previously published reference material (14) using the Mann-Whitney U test. All the values expressed for the sensibility index in the results are the mean of 4 fingers unless otherwise stated.

\section{Results}

The results of the analyses based on both hands and on the right hand only were essentially similar. For the most part, only the results based on the analysis of both hands have been presented. For the material as a whole there

Table 1. Sensibility index (SI) expressed as the mean of the index and little fingers of both hands, the percentage of patients with a mean $\mathrm{SI}$ of $<0.8$, and the percentage of patients with an $\mathrm{SI}$ of $<0.8$ for at least one finger in relation to sensorineural symptoms (SN), vibration white finger (VWF), and combinations of both $(S N+V W F)$ among 96 vibration-exposed men.

\begin{tabular}{|c|c|c|c|c|}
\hline & \multirow[t]{2}{*}{$\begin{array}{l}\text { Number of } \\
\text { patients }\end{array}$} & \multicolumn{2}{|c|}{$\begin{array}{l}\text { Mean of } \\
\text { four fingers }\end{array}$} & \multirow{2}{*}{$\begin{array}{c}\begin{array}{c}\text { In at least } \\
\text { one finger }\end{array} \\
\mathrm{SI} \\
<0.8(\%)\end{array}$} \\
\hline & & $\mathrm{SI}$ & $\begin{array}{c}S \mid \\
<0.8(\%)\end{array}$ & \\
\hline Whole material & 96 & 0.71 & 57.3 & 72.9 \\
\hline $\begin{array}{l}\text { SN symptoms } \\
\text { WWF } \\
\text { SN symptoms }\end{array}$ & $\begin{array}{l}45 \\
21\end{array}$ & $\begin{array}{l}0.72 \\
0.78\end{array}$ & $\begin{array}{l}57.8 \\
47.6\end{array}$ & $\begin{array}{l}68.9 \\
76.2\end{array}$ \\
\hline \multicolumn{5}{|l|}{$\begin{array}{l}\text { Patients with SN } \\
\text { symptoms only }\end{array}$} \\
\hline $\begin{array}{l}\text { Cold intolerance } \\
\text { No cold intolerance }\end{array}$ & $\begin{array}{r}25 \\
20\end{array}$ & $\begin{array}{l}0.65 \\
0.79\end{array}$ & $\begin{array}{l}76.0 \\
35.0\end{array}$ & $\begin{array}{l}80.0 \\
55.0\end{array}$ \\
\hline $\begin{array}{l}\text { Patients with } \\
\text { bilateral symptoms }\end{array}$ & 67 & 0.66 & 65.7 & 77.6 \\
\hline $\begin{array}{l}\text { Patients with } \\
\text { unilateral symptoms }\end{array}$ & 29 & 0.81 & 37.9 & 62.1 \\
\hline
\end{tabular}

Scand J Work Environ Health 1998, vol 24, no 6 
was a substantial increase in the perception thresholds for vibration (table 1), differing significantly ( $\mathrm{P}<0.0001$ ) from the previously published normal material (14). The mean sensibility index for all the patients was 0.71 . For $57.3 \%$ of the patients it (mean of 4 fingers) was below 0.8 , and for $72.9 \%$ the sensibility index was below 0.8 for at least 1 finger (table 1, figure 3 ).

Exposure time affected the sensibility index only slightly. The groups exposed to vibration for $0-10$ and $11-20$ years showed a mean sensibility index of 0.73 . For the patients exposed for $21-30$ years the index was 0.67 , and for those exposed for $\geq 30$ years it was 0.70 . There were no statistical differences between the groups $(\mathrm{P}=0.85)$.

There were 45 patients with sensorineural symptoms only, 21 with vibration white finger only, and 30 with a combination of both (table 1). The analysis of variance showed no statistical differences between the 3 groups or for the material as a whole $(\mathrm{P}=0.20)$, for patients with bilateral symptoms $(\mathrm{P}=0.30)$ or for patients with unilateral symptoms $(\mathrm{P}=0.99)$. For a considerable number of patients within each group the mean sensibility index was below 0.8 (table 1 ). The groups did not differ from each other in this respect either $(\mathrm{P}=0.53)$.

Cold intolerance occurred in 25 of the 45 patients with sensorineural symptoms only. The mean sensibility

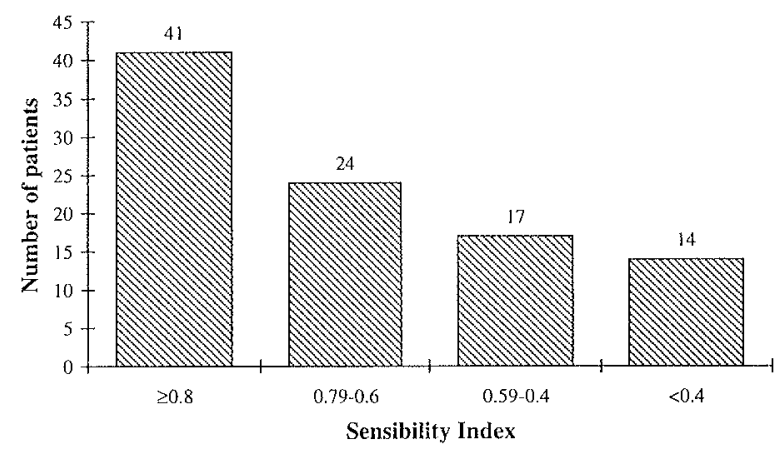

Figure 3. Diagram presenting the distribution of the sensibility index for the whole material.

Table 2. Sensibility index (SI) expressed as the mean of the index and little fingers of both hands for 96 vibration-exposed men in relation to the sensorineural (SN) stages of the Stockholm Workshop Scale.

\begin{tabular}{|c|c|c|c|c|c|c|c|c|}
\hline & \multicolumn{8}{|c|}{ SN stage } \\
\hline & \multicolumn{2}{|c|}{0} & \multicolumn{2}{|c|}{1} & \multicolumn{2}{|c|}{2} & \multicolumn{2}{|c|}{3} \\
\hline & $\begin{array}{c}\text { Number } \\
\text { of } \\
\text { patients }\end{array}$ & $\mathrm{SI}$ & $\begin{array}{c}\text { Number } \\
\text { of } \\
\text { patients }\end{array}$ & SI & $\begin{array}{l}\text { Number } \\
\text { of } \\
\text { patients }\end{array}$ & SI & $\begin{array}{c}\text { Number } \\
\text { of } \\
\text { patients }\end{array}$ & SI \\
\hline \multicolumn{9}{|l|}{ Whole } \\
\hline material & 21 & 0.78 & 32 & 0.77 & 31 & 0.69 & 12 & 0.48 \\
\hline SN & - & . & 18 & 0.76 & 22 & 0.73 & 5 & 0.50 \\
\hline$S N+V W F$ & - & . & 14 & 0.77 & 9 & 0.58 & 7 & 0.46 \\
\hline
\end{tabular}

index for the patients with cold intolerance was 0.65 , compared with 0.79 for those without (table 1 ). The analysis of variance showed a significant difference between the 2 groups $(\mathrm{P}=0.03)$. The mean sensibility index of $<0.8$ was significantly more common for patients with cold intolerance $(\mathrm{P}<0.01)$ (table 1$)$. For all the examined fingers, with the exception of the right index finger, the sensibility index was significantly lower for the patients with cold intolerance $(\mathrm{P}<0.01)$.

Increasingly advanced sensorineural stages were accompanied by a decreasing sensibility index (table 2). There was a statistically significant decrease in the sensibility index from stage 0 to 3 and from stage 1 to 3 $(\mathrm{P}<0.01)$. No statistically significant changes in the sensibility index occurred between the stages of vibration white finger (table 3) $(\mathrm{P}=0.45)$. Category 4 for vibration white finger was not included in the analysis because it contained only one patient.

The analysis of variance showed that there were significant differences in the sensibility index between the 4 examined fingers $(\mathrm{P}<0.0001)$ (table 4$)$. The sensibility index was significantly lower for the right hand than for the left in the whole material $(\mathrm{P}=0.0001)$, for the patients with bilateral symptoms $(\mathrm{P}=0.04)$, and for the patients with unilateral symptoms ( $\mathrm{P}=0.01$ ) (table 4$)$. Furthermore, the sensibility index was significantly lower for the fingers innervated by the ulnar nerve than for those innervated by the median nerve. This was the case for the whole material $(\mathrm{P}<0.0001)$, for the patients with bilateral symptoms $(\mathrm{P}<0.0001)$, and for the patients with unilateral symptoms $(\mathrm{P}=0.04)$ (table 4$)$, as well as for the right hand only $(\mathrm{P}=0.001)$.

The patients with bilateral symptoms had a significantly lower sensibility index $(\mathrm{P}<0.01)$ than the patients with unilateral symptoms (tables 1 and 4). This was also true in a comparison of the symptomatic right hands only for these patients $(\mathrm{P}=0.01)$.

The results for vibrotactile sense versus further neural, muscular and vascular symptoms and signs are given in table 5. There was significant impairment of vibrotactile sense in the patients with increased 2-point discrimination (figure 4), weakness of the intrinsic muscles, and reduced grip strength. No differences were found between the patients with or without nocturnal paresthesia, a positive Tinel sign, a positive Phalen test, pain, or a positive Allen test.

\section{Discussion}

To prevent the development of serious and perhaps irreversible symptoms due to vibration exposure, early detection of injury is important. The difficulty is illustrated by the many methods in use to diagnose the neurological component of the hand-arm vibration syndrome, 
Table 3. Sensibility index (SI) expressed as the mean of the index and little fingers of both hands for the 96 vibration-exposed men in relation to vibration white finger (VWF) stages on the Stockholm Workshop Scale.

\begin{tabular}{|c|c|c|c|c|c|c|c|c|c|c|}
\hline & \multicolumn{10}{|c|}{ VWF scale } \\
\hline & \multicolumn{2}{|c|}{0} & \multicolumn{2}{|c|}{1} & \multicolumn{2}{|c|}{2} & \multicolumn{2}{|c|}{3} & \multicolumn{2}{|c|}{4} \\
\hline & $\begin{array}{l}\text { Number } \\
\text { of patients }\end{array}$ & SI & $\begin{array}{l}\text { Number } \\
\text { of patients }\end{array}$ & SI & $\begin{array}{l}\text { Number } \\
\text { of patients }\end{array}$ & SI & $\begin{array}{l}\text { Number } \\
\text { of patients }\end{array}$ & SI & $\begin{array}{l}\text { Number } \\
\text { of patients }\end{array}$ & SI \\
\hline Whole material & 45 & 0.72 & 11 & 0.81 & 23 & 0.67 & 16 & 0.68 & 1 & 0.39 \\
\hline WWF & - & & 3 & 0.91 & 10 & 0.74 & 8 & 0.78 & - & . \\
\hline$S N+V W F$ & - & & 8 & 0.77 & 13 & 0.62 & 8 & 0.58 & 1 & 0.39 \\
\hline
\end{tabular}

Table 4. Sensibility index (SI) of the index (II) and little (V) fingers of the right and left hands, the mean SI of the right and left hands, and the mean SI of fingers innervated by the median and the ulnar nerves for the 96 vibration-exposed men.

\begin{tabular}{|c|c|c|c|c|c|c|c|c|}
\hline & \multicolumn{2}{|c|}{ Right hand } & \multicolumn{2}{|c|}{ Left hand } & \multicolumn{2}{|c|}{ Hand } & \multicolumn{2}{|c|}{ Nerve } \\
\hline & II & V & ॥ & V & Right & Left & Median & Ulnar \\
\hline Whole material & 0.71 & 0.67 & 0.75 & 0.69 & 0.69 & 0.72 & 0.73 & 0.68 \\
\hline $\begin{array}{l}\text { SN } \\
\text { VWF } \\
\text { SN + VWF }\end{array}$ & $\begin{array}{l}0.70 \\
0.77 \\
0.69\end{array}$ & $\begin{array}{l}0.69 \\
0.71 \\
0.60\end{array}$ & $\begin{array}{l}0.77 \\
0.83 \\
0.68\end{array}$ & $\begin{array}{l}0.70 \\
0.78 \\
0.60\end{array}$ & $\begin{array}{l}0.70 \\
0.75 \\
0.64\end{array}$ & $\begin{array}{l}0.73 \\
0.80 \\
0.64\end{array}$ & $\begin{array}{l}0.74 \\
0.80 \\
0.68\end{array}$ & $\begin{array}{l}0.70 \\
0.76 \\
0.60\end{array}$ \\
\hline \multicolumn{9}{|l|}{ Patients with SN only } \\
\hline $\begin{array}{l}\text { Cold intolerance } \\
\text { No cold intolerance }\end{array}$ & $\begin{array}{l}0.69 \\
0.72\end{array}$ & $\begin{array}{l}0.62 \\
0.78\end{array}$ & $\begin{array}{l}0.70 \\
0.85\end{array}$ & $\begin{array}{l}0.62 \\
0.81\end{array}$ & $\begin{array}{l}0.65 \\
0.76\end{array}$ & $\begin{array}{l}0.65 \\
0.83\end{array}$ & $\begin{array}{l}0.69 \\
0.79\end{array}$ & $\begin{array}{l}0.62 \\
0.80\end{array}$ \\
\hline Patients with bilateral symptoms & 0.67 & 0.62 & 0.71 & 0.63 & 0.65 & 0.67 & 0.69 & 0.63 \\
\hline Patients with unilateral symptoms & 0.80 & 0.76 & 0.86 & 0.82 & 0.79 & 0.84 & 0.83 & 0.80 \\
\hline
\end{tabular}

such as measurement of esthesiometric thresholds (16), assessment of temperature thresholds (17), combined methods (18), and neurophysiological measurement of fractionated nerve conduction $(19,20)$. Tests assessing the vibrotactile sense of the fingertips reflect sensorineural dysfunction in the hand and arm regardless of the level of the lesion. Such tests respond very early to both compression and vibration-induced nerve injury $(8$, 9). They reflect dysfunction mainly in the rapidly adapting receptors in the fingertips or the corresponding nerve fiber components, which are large myelinated $A B$ nerve fibers (21). In analogy with audiometry we prefer to perform the test using multiple frequencies $(9,12)$, since the various mechanoreceptive units of the skin respond within different frequency ranges (22). The tactilogram principle therefore appears well suited for obtaining an overall picture of the vibrotactile sense and therefore also of sensorineural dysfunction of the hand, thereby contrasting with single frequency measurements (10).

The symptoms of the hand-arm vibration syndrome tend to progress with time as vibration exposure continues (3), but, in our material, the sensibility index did not change with exposure time. Since the patients constituted a selected group of symptomatic persons, the exposure time did not mirror the natural course of the injury, but rather the point in time when the patients sought medical advice. Exposure time may therefore reflect individ-

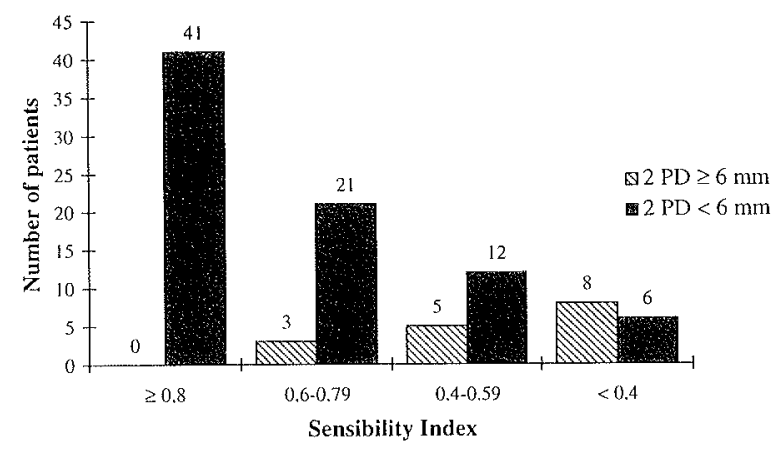

Figure 4. Diagram presenting the distribution of the sensibility index for patients with increased or normal 2-point discrimination (2PD).

ual sensitivity to vibration, which varies within wide boundaries (5).

There was considerable impairment of the vibrotactile sense both in patients with sensorineural symptoms only and in patients with vibration white finger only, a finding suggesting a high degree of neural involvement even in patients suffering from predominantly vasospastic symptoms. A possible explanation for this phenomenon may be the close proximity of the finger tips to the vibrating source, a situation leading to a certain degree of neural injury common to all the patients and thus making the distinction between them difficult. However, the progression of sensorineural symptoms was accompanied by a decrease in the sensibility index, whereas the pro- 
Table 5. Number of patients and the sensibility index (SI) expressed as the mean of the index and little fingers of both hands and the percentage of the number of patients with an $\mathrm{SI}$ of $<0.8$ in relation to the presence (Yes) and absence (No) of clinical symptoms and signs among the 96 vibration-exposed men.

\begin{tabular}{|c|c|c|c|c|c|c|c|c|}
\hline \multirow[t]{3}{*}{ Symptom or sign } & \multicolumn{8}{|c|}{ Presence of clinical symptoms and signs } \\
\hline & \multicolumn{2}{|c|}{$\begin{array}{l}\text { Number } \\
\text { of patients }\end{array}$} & \multicolumn{3}{|c|}{ Mean SI } & \multicolumn{3}{|c|}{$\begin{array}{c}\mathrm{Sl}<0.8 \\
(\%)\end{array}$} \\
\hline & Yes & No & Yes & No & P-value & Yes & No & P-value \\
\hline 2-Point discrimination $\geq 6 \mathrm{~mm}$ & 16 & 80 & 0.40 & 0.77 & $<0.0001$ & 100.0 & 48.8 & $<0.0001$ \\
\hline Intrinsic weakness & 9 & 87 & 0.34 & 0.74 & $<0.0001$ & 100.0 & 52.9 & $<0.01$ \\
\hline Reduced grip strength & 17 & 79 & 0.54 & 0.74 & $<0.01$ & 76.5 & 53.2 & $>0.05$ \\
\hline Bilateral symptoms & 67 & 29 & 0.66 & 0.81 & $<0.01$ & 65.7 & 37.9 & 0.01 \\
\hline Nocturnal paresthesia & 38 & 58 & 0.72 & 0.70 & $>0.05$ & 52.6 & 60.3 & $>0.05$ \\
\hline Positive Tinel's sign & 21 & 75 & 0.67 & 0.72 & $>0.05$ & 61.9 & 56.0 & $>0.05$ \\
\hline Positive Phalen's test & 26 & 70 & 0.68 & 0.72 & $>0.05$ & 57.7 & 57.1 & $>0.05$ \\
\hline Pain & 21 & 75 & 0.64 & 0.73 & $>0.05$ & 76.2 & 52.0 & $>0.05$ \\
\hline Positive Allen's test & 24 & 72 & 0.68 & 0.72 & $>0.05$ & 70.8 & 52.8 & $>0.05$ \\
\hline
\end{tabular}

gression of vibration white finger appeared to take place independently of the sensory changes accompanying increasingly severe sensorineural symptoms. This view is further supported by our finding that the sensibility index was not affected by the presence of a positive Allen test (23). If a nerve injury were responsible for vibration white finger, it would probably be an injury to the sympathetic fibers of small diameter, which are regulators of vascular tone (24). Such an injury would not be reflected in the sensibility index since neural information pertaining to the vibrotacile sense is mediated by fibers of larger diameter (21).

Cold intolerance, which is not included in the Stockholm Workshop Scale (2), may be present in any sensorineural stage (6). Since it is difficult to judge the presence or absence of it in persons who suffer from vibration white finger, we analyzed the cold intolerance of the 45 patients suffering from sensorineural symptoms only. Although patients subjectively often experience cold intolerance as a vascular symptom, it is usually a strong indication of nerve injury following, for instance, finger amputation, nerve transection (25), or reflex sympathetic dystrophy. Our findings indicate that cold intolerance may be a sign of substantial neural involvement in vibration-exposed patients also, since it was found to be associated with considerable impairment of the vibrotactile sense.

In the material as a whole the examined fingers differed from each other, as did the right and left hands and fingers innervated by the median and ulnar nerves (18). In a comparison between patients with and without cold intolerance, the right index finger was the finger that did not differ significantly between the 2 groups. Consequently, the right index finger should not be used alone to monitor changes in vibrotactile sense, as it appears not to reflect vibration-induced sensory dysfunction so well as the other fingers do. We recommend that the sensibility index be measured as the mean of 4 fingers.
The reasons for the different behavior of the right index finger are obscure, but ergonomic factors related to the work situation may be worth considering. A conceivable explanation for the different characteristics of the right index finger may be that, in right-handed patients such as those in our material in particular (93 out of 96), it is frequently used to compress the trigger mechanism of the vibrating tool. This action would be expected to require less force than grasping the handle, which thereby reduces the amount of energy conveyed to the finger. Similarly, ergonomic factors may be involved in the changes corresponding to the ulnar nerve. As it is more superficial and less protected than the median nerve, it would be more subjected to direct trauma. In addition, the 2 most ulnar fingers grasp the handle of the tool with great force in a closing grip made possible by the mobility of the 4th and 5 th carpometacarpal joints. However, to obtain a picture of both median and ulnar nerve function, a set of fingers - such as in this study - should be examined.

Of special interest is the high frequency of impaired vibrotactile sense in cases of normal 2-point discrimination (figure 4). For roughly half of these cases (48.8\%), the sensibility index was below 0.8 . Many of these patients had an extremely low sensibility index. This finding supports the view that the 2-point discrimination test is questionable and of limited value for detecting early cases of the hand-arm vibration syndrome, since even advanced cases of vibration-induced sensorineural symptoms may have normal 2-point discrimination (6). The findings, analogous to what is found in nerve compression injuries, are explained by the fact that 2-point discrimination is, to a great extent, based on central nervous interpretation (26). Only when the mechanoreceptive units mediating spatial resolution are damaged seriously enough is 2-point discrimination affected. This finding is reflected in the lower frequencies of the tactilogram. Since such changes appear late, well after changes in the 
higher frequencies, the sensibility index is usually severely affected. In our material all the patients with elevated 2-point discrimination had a pathological sensibility index.

The patients with bilateral symptoms had significantly more severe impairment of the vibrotactile sense than the patients with unilateral symptoms. One might be tempted to assume that the nonsymptomatic hand would perhaps shift the mean sensibility index toward a higher value. In a separate analysis of symptomatic right hands only ( 5 of the 29 patients with unilateral symptoms were asymptomatic on the right side) the difference persisted. This finding would suggest that bilateral symptoms are a sign of more advanced neural injury.

The muscular weakness frequently seen in the handarm vibration syndrome is typically not accompanied by muscular atrophy even in severe cases $(27,28)$. Still, structural changes have been reported (29). In our material, both weakness of the intrinsic muscles and reduced grip strength - subjectively assessed by the examiner - were associated with a significantly reduced sensibility index. This phenomenon occurred exclusively in patients with sensorineural symptoms and therefore indicated a strong connection between muscular weakness and nerve injury. Further study of this association, with a more exact dynamometric evaluation of strength, is necessary.

Symptoms and signs of median nerve involvement in the carpal tunnel were not related to any further decrease in the sensibility index. A plausible explanation is that all the patients with neuropathy in our material probably suffer from dysfunction of the sensory receptors of the fingers and the finger tips, as their closeness to the vibrating source is likely to predispose to injury. An additional nerve lesion at the level of the carpal tunnel would therefore add little to an established impairment of the vibrotactile sense. The presence or absence of such a nerve lesion could not be confirmed in our material, however, since no fractionated nerve conduction tests were done. A separate study on the subject has been published (30).

\section{Concluding remarks}

A considerable neural component is present in all symptomatic vibration-exposed patients, including those with predominantly vasospastic problems. As symptoms progress, the severity of sensorineural symptoms is reflected in the sensibility index, whereas that of vibration white finger is not. In patients with sensorineural symptoms, clinical median nerve involvement in the carpal tunnel does not affect the sensibility index, probably due to injury to the mechanoreceptive units of the fingers and fingertips. Bilateral symptoms, muscular weakness, and increased 2-point discrimination indicate more advanced disease. The presence of cold intolerance is strongly re- lated to nervous involvement and should be noted in the patient history. All examined fingers differ from each other. The right hand and fingers innervated by the ulnar nerve are more affected than the left hand and fingers innervated by the median nerve. Therefore, the tactilometric examination of one finger only should be avoided as the result may be misleading. On the contrary, it is necessary to examine several fingers in order to include the median and the ulnar nerves of both hands.

\section{Acknowledgments}

The study was supported by grants from the Swedish Council for Work Life Research (number 96-0742), the Swedish Medical Research Council (5188), and grants from the Malmö University Hospital.

We thank associate professor Björn Holmquist, Department of Mathematical Statistics, University of Lund, for his statistical advice.

\section{References}

1. Brammer AJ, Taylor W, Lundborg G. Sensorineural stages of the hand-arm vibration syndrome. Scand J Work Environ Health 1987; 13:279-83.

2. Gemne G, Pyykkö I, Taylor W, Pelmear PL. The Stockholm Workshop scale for the classification of cold-induced Raynaud's phenomenon in the hand-arm vibration syndrome (revision of the Taylor-Pelmear scale). Scand J Work Environ Health 1987;13:275-8.

3. Östman F, Lundborg G, Bornmyr S, Lilja B. Is vibrationinduced white finger a reversible syndrome if vibration is stopped? J Hand Surg 1996;21 B:750-2.

4. Bovenzi M, Franzinelli A, Scattoni I, Vannuccini I. Hand-arm vibration syndrome among travertine workers: a follow up study. Occup Environ Med 1994;51:361-5.

5. Gemne G, Lundström R. ISO 5349: validity of frequency weighting and model for white finger risk prediction. In: Gemne G, Brammer AJ, Hagberg M, Lundström R, Nilsson $\mathrm{T}$, ed. Proceedings of the Stockholm Workshop 94. Hand-arm vibration syndrome: diagnostics and quantitative relationships to exposure. May 25-28, 1994. Stockholm: Arbetarskyddsverket, 1995:33-45. Arbete och hälsa, no 5.

6. Anonymous. Clinical and laboratory diagnostics of neurological disturbances in workers using hand-held vibrating tools. In: Gemne G, Brammer AJ, Hagberg M, Lundström R, Nilsson T, ed. Proceedings of the Stockholm Workshop 94. Handarm vibration syndrome: diagnostics and quantitative relationships to exposure. May 25-28, 1994. Stockholm: Arbetarskyddsverket, 1995:187-93. Arbete och Hälsa, no 5.

7. Brammer AJ, Piercy JE, Auger PL. Assessment of impaired tactile sensation: a pilot study. Scand J Work Environ Health 1987:13:380-4.

8. Lundborg G, Lie-Stenström AK, Sollerman C, Strömberg T, Pyykkö J. Digital vibrogram: a new diagnostic tool for sensory testing in compression neuropathy. J Hand Surg 
1986;11A:693-9.

9. Lundborg G, Sollerman C, Strömberg T, Pyykkö I, Rosén B. A new principle for assessing vibrotactile sense in vibrationinduced neuropathy. Scand J Work Environ Health 1987;13:375-9.

10. Goldberg JM, Lindblom U. Standardized method of determining vibratory perception thresholds for diagnosis and screening in neurological investigation. J Neurol Neurosurg Psych 1979;42:793-803.

11. Lundborg G, Dahlin LB, Lundström R, Necking LE, Strömberg $\mathrm{T}$. Vibrotactile function of the hand in compression and vibration-induced neuropathy: sensibility index - a new measure. Scand J Plast Reconstr Hand Surg 1992;26(3):27581.

12. Virokannas H. Vibration perception thresholds in workers exposed to vibration. Int Arch Occup Environ Health 1992;64:377-82.

13. Wenemark M, Lundström R, Hagberg M, Nilsson T. Vibrotactile perception thresholds as determined by two different devices in a working population. Scand $\mathrm{J}$ Work Environ Health 1996;22:204-10.

14. Lundström R, Strömberg T, Lundborg G. Vibrotactile perception threshold measurements for diagnosis of sensory neuropathy: description of a reference population. Int Arch Occup Environ Health 1992;64:201-7.

15. Gibbons JD. Nonparametric Methods for Quantitative Analysis. New York (NY): Holt, Rinehart and Winston, 1976.

16. Bovenzi M, Zadini A. Quantitative estimation of aesthesiometric thresholds for assessing impaired tactile sensation in workers exposed to vibration. Int Arch Occup Environ Health $1989 ; 61: 431-5$.

17. Ekenvall L, Nilsson BY, Gustavsson P. Temperature and vibration thresholds in vibration syndrome. $\mathrm{Br} J$ Ind $\mathrm{Med}$ 1986;43:825-9.

18. McGeoch K, Gilmour WH, Taylor W. Sensorinenral objective tests in the assessment of hand-arm vibration syndrome. Occup Environ Med 1994;51:57-61.

19. Kimura J. A method for determining median nerve conduc.tion velocity across the carpal tunnel. J Neurol Sci 1978:38:1-10.
20. Hjortsberg U, Rosén I, Ørbak P, Lundborg G, Balogh I. Finger receptor dysfunction in dental technicians exposed to high-frequency vibration. Scand J Work Environ Health $1989 ; 15: 339-44$.

21. Dellon AL. Evaluation of Sensibility and Re-education of Sensation in the Hand. Baltimore (MA): Williams \& Wilkins, 1981.

22. Lundström R, Johansson RS. Acute impaiment of the sensitivity of skin mechanoreceptive units caused by vibration exposure of the hand. Ergonomics 1986;29:687-.98.

23. Nilsson T, Burström L, Hagberg M. Risk assessment of vibration exposure and white fingers among platers. Int Arch Oc. cup Environ Health 1989;61:473-81.

24. Sunderland S. Chapter 5: nerve fibres. In: Nerve injuries and their repair: a critical appraisal. Edinburgh: Churchill Livingstone, 1991:17-26.

25. Birch R, Raji A. Repair of median and ulnar nerves. Primary suture is best. J Bone Joint Surg 1991;73B:154-7.

26. Lundborg $\mathrm{G}$, Rosén $\mathrm{B}$. Rationale for quantitative sensory tests in hand surgery. In: Boivie $J$, Hansson $P$, Lindblom $U$, ed. Touch, temperature and pain in health and disease: mechanisms and assessments. Seattle (WA): IASP Press, 1994:151-62.

27. Färkkilä MA, Pyykkö I, Starck JP, Korhonen OS. Hand grip forces and muscle fatigue in the etiology of the vibration syndrome. In: Brammer A, Taylor W, ed. Vibration effects on the hand and arm in industry. New York (NY): John Wiley \& Sons, 1982:45-50.

28. Färkkilä M, Aatola S, Starck J, Korhonen O, Pyykkö I. Handgrip force in lumberjacks: two-year follow-up. Int Arch Occup Environ Health 1986;58:203-8.

29. Necking LE, Dahlin LB, Fridén J, Lundborg G, Lundström R, Thornell LE. Vibration-induced muscle injury. An experimental model and preliminary findings. J Hand Surg $1992 ; 17 \mathrm{~B}: 270-4$

30. Strömberg T, Dahlin LB, Rosén I, Lundborg G. Neurophysiological findings in vibration-exposed male workers. $J$ Hand Surg [Br]. In press.

Received for publication: 16 June 1998 